\title{
Henoch-Schönlein Purpura Associated with Pulmonary Mycobacterium avium-intracellulare Complex
}

\author{
Shuichi YANO
}

\begin{abstract}
A 57-year-old woman presented with bloody sputum and high grade fever. She had been treated for Mycobacterium avium-intracellulare complex (MAC). High grade fever slightly decreased and bloody sputum disappeared after two weeks, but low grade fever persisted. After 3 days of recurrence of bloody sputum, she suddenly complained of palpable pururitic lesions on the bilateral lower extremities with bilateral gonalgia. Although there are some reports of direct skin lesions due to MAC, there are no reports of hypersensitivity vasculitis, Henoch-Schönlein purpura, in MAC. It is necessary to consider MAC infection as a potential cause of Henoch-Schönlein purpura.
\end{abstract}

(Internal Medicine 43: 843-845, 2004)

Key words: Skin lesion, Nontuberculous mycobacterium

\section{Introduction}

Although Henoch-Schönlein purpura due to Mycobacterium tuberculosis has been reported previously, it is uncommon. And there were some reports of direct skin lesions due to Mycobacterium avium-intracellulare complex (MAC). However, to date there are no reports of Henoch-Schönlein purpura in MAC. This is the first report of HenochSchönlein purpura associated with MAC infection. We should consider MAC infection as a potential cause of Henoch-Schönlein purpura.

\section{Case Report}

A 57-year-old woman, a housekeeper, had been treated for MAC with various antituberculous drugs for 11 years. Oxygen therapy was initiated in December 1998 and clarithromycin was added in November 2001. Chest radiograph showed bilateral destroyed lung with multiple cystic lesions (Fig. 1). The patient demonstrated right pneumothorax and received bullectomy in 1998.

She presented with bloody sputum and high grade fever on 11 March 2002 . The temperature was $38.1^{\circ} \mathrm{C}$. Analysis of arterial blood gases with nasal prongs at $3 l / \mathrm{min}$ showed that the partial pressure oxygen was $89.9 \mathrm{mmHg}$, the partial pressure of carbon dioxide was $49.6 \mathrm{mmHg}$, and the $\mathrm{pH}$ was 7.39. The white blood cell count was $11,400 / \mathrm{mm}^{3}, 80 \%$ neutrophils, $13 \%$ lymphocytes, $7 \%$ monocytes. The serum albumin level was $4.0 \mathrm{~g} / \mathrm{dl}$ and the CRP level was $5.0 \mathrm{mg} / \mathrm{dl}$. Platelets were $357,000 / \mathrm{mm}^{3}$. Sputum culture yielded Mycobacterium (M.) avium and $M$. intracellulare. Since high grade fever continued, panipenem and fosfomycin were used for two weeks. The high grade fever was slightly lowered and bloody sputum disappeared, but a low grade fever persisted. After 3 days of recurrence of bloody sputum, the patient suddenly complained of palpable pururitic lesions on the bilateral lower extremities with bilateral gonalgia on 16 April (Fig. 2). Mainly dot hemorrhage with erythema spread to the bilateral dorsum pedis, lower leg and thigh, and the erythema did not fade by pressing with glass. It was partially accompanied by pigmentation. Platelet count was 329,000/ $\mathrm{mm}^{3}$. Prothrombin time and partial thromboplastin time were normal. Serum antistreptolysin-O (ASO) was normal. Urine showed microhematuria. Styptic drugs and vitamin $\mathrm{C}$ were administered and the skin lesions were slightly improved. However, purpura recurred and worsened with microhematuria after 9 days. Therefore, $10 \mathrm{mg}$ prednisolone was added. The purpura improved and prednisolone was decreased to $5 \mathrm{mg}$ after 5 days. Prednisolone persisted, and there was no recurrence of purpura or bloody sputum.

\section{Discussion}

Henoch-Schönlein purpura is a leukocytoclastic vasculitis that usually affects children. Palpable pururitic lesions, ab-

From the Department of Pulmonary Medicine, Matsue National Hospital, Matsue

Received for publication November 28, 2003; Accepted for publication May 14, 2003

Reprint requests should be addressed to Dr. Shuichi Yano, the Department of Pulmonary Medicine, Matsue National Hospital, 5-8-31 Agenogi, Matsue, Shimane 690-8556 


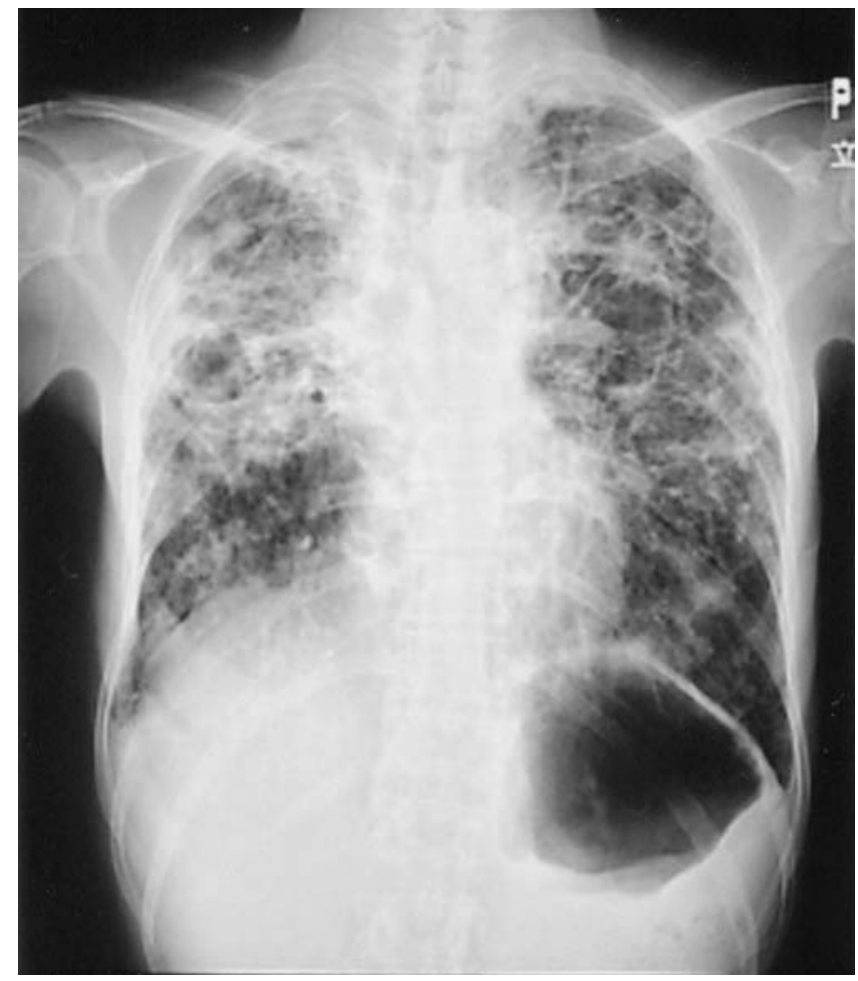

Figure 1. Chest radiograph on admission showing diffuse multiple cystic lesions.

dominal pain, and arthritis of the knees and ankles are common findings, but other organs may be involved as well. Several precipitating factors have been implicated, including infections, environmental chemicals, toxins, insect bites, physical trauma, complement $\mathrm{C}_{2}$ deficiency, and malignancies (1).

Infections are proposed to be a causative factor and leukocytoclastic vasculitis due to $M$. tuberculosis has been reported previously (2-5), but is uncommon (6). There are two types of skin lesions associated with tuberculosis (7):

(1)Direct lesions where the bacillus is present, produced by three different mechanisms (inoculation from an exogenous source; cutaneous mycobacteriosis from an endogenous source, either by contiguous spread or by autoinoculation and third, those arising from hematogenous spread, such as lupus vulgaris, acute hematogenous dissemination and nodules or abscess.

(2)Hypersensitivity vasculitis, where the microorganism has never been found and the proposed pathogenic mechanism is the deposit (in the walls of small vessels) of immune complexes formed by antibodies to M. tuberculosis proteins (8). Henoch-Schönlein purpura is thought to be an immune complex disease, with $50 \%$ of patients producing $\operatorname{IgA}$ rheumatoid factor (9).

There have been some reports of direct skin lesions due to MAC (10-12). However, there are no reports of hypersensitivity vasculitis, Henoch-Schönlein purpura, in MAC. In the

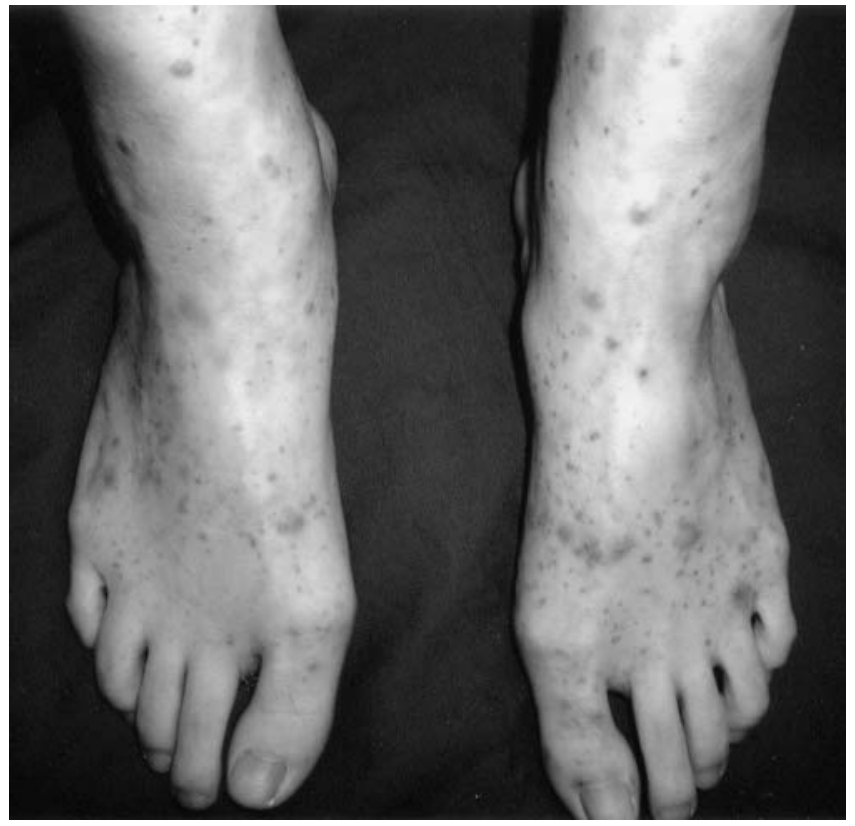

Figure 2. Macroscopic view of the cutaneous vasculitis lesions on the legs.

present case, the involvement of drugs was thought to be negative as a cause of the skin lesions, because there has not been any change in the drugs over 1 year. Since her condition has been continuously poor due to MAC infection, some immune response to the MAC infection might have contributed to the skin lesions. The fact that the steroid was effective also proves this possibility. As there were some reports of pulmonary hemorrhage in Henoch-Schönlein purpura, there might be some relation to the bloody sputum in this case. Henoch-Schönlein purpura may promote serious renal disturbance, and it is important to have an early diagnosis and treatment. It is also necessary to consider MAC infection as a potential cause of Henoch-Schönlein purpura.

\section{References}

1) Hoffman R, Benz EJ, Shattil SJ, Furie B, Cohen HJ, Shiberstein LE (eds). Hematology, 2nd ed. New York, Churchill Livingstone, 1995: 1619.

2) Pacheco A, Mateos P, Medina J, Guisasola L, Carrillo F, Perez-Oteiza J. Pulmonary tuberculosisde Schönlein-Henoch purpura. Rev Clin Esp 180: 515, 1987 (in Spanish).

3) Visser AJ, Heyl T. Skin tuberculosis as seen at Ga-Rankuwa Hospital. Clin Exp Dermatol 18: 507-515, 1993.

4) Sais G, Vidaller A, Jucgla A, Peyri J. Tuberculous lymphadenitis presenting with cutaneous leukocytoclastic vasculitis. Clin Exp Dermatol 21: 65-66, 1996.

5) Chan CHS, Chong YW, Sun AJ, Hoheisel GB. Cutaneous vasculitis associated with tuberculosis and its treatment. Tubercle 71: 297-300, 1990.

6) Lee A, Jang J, Lee K. Two cases of leukocytoclastic vasculitis with tuberculosis. Clin Exp Dermatol 23: 225-226, 1998. 


\section{Henoch-Schönlein Purpura in Mycobacterium avium-intracellulare Complex (MAC) Patient}

7) Byet BE Jr, Orbals DW, Santa Cruz DJ, Kobayashi GS, Eisen AZ, Medoff G. Cutaneous mycobacteriosis: analysis of 34 cases with a new classification of the disease. Medicine (Baltimore) 60: 95-109, 1980.

8) Minguez P, Pintor P, Buron R, Diaz-Pollan B, Puche JJ, Pontes JC. Pulmonary tuberculosis presenting with cutaneous leukocytoclastic vasculitis. Infection 28: 55-57, 2000.

9) Mackel SE, Jordon RE. Leukocytocrastic vasculitis. A cutaneous expression of immune complex disease. Arch Dermatol 118: 296-301, 1982.

10) Kullavanijaya $P$, Sirimachan $S$, Surarak S. Primary cutaneous infection with Mycobacterium avium intracellulare complex resembling lupus vulgaris. Br J Dermatol 136: 264-266, 1997.

11) Clark JA, Margolis DM. A cutaneous lesion in a patient with AIDS: an unusual presentation of infection due to Mycobacterium avium complex. Clin Inf Dis 16: 555-557, 1993.

12) Sagerman PM, Relman DA, Niroomand F, Niedt GW. Localization of Mycobacterium avium-intracellulare within a skin lesion bacillary angiomatosis in a patient with AIDS. Diagn Mol Pathol 1: 212-216, 1992. 